\title{
Small Intestinal Mucinous Adenocarcinoma
}

National Cancer Institute

\section{Source}

National Cancer Institute. Small Intestinal Mucinous Adenocarcinoma. NCI Thesaurus. Code C43536.

An invasive adenocarcinoma that arises from the small intestine. It is composed of malignant glandular cells which contain intracytoplasmic mucin. Often, the infiltrating glandular structures are associated with mucoid stromal formation. 